\title{
A performance musical das pessoas com deficiência visual
}

\author{
Shirlei Escobar Tudissaki \\ Universidade Estadual Paulista
}

\begin{abstract}
Resumo
Este artigo teve como objetivo focalizar algumas das questões envolvidas na performance musical de pessoas com deficiência visual, a saber: os tipos de deficiência visual (baixa visão e cegueira; deficiência visual congênita e adquirida); a musicografia braille; os tipos de memória; a memória musical; e como se desenvolve a memória para o músico com deficiência visual. Para tanto, foi realizada uma pesquisa qualitativa/quantitativa, utilizando a entrevista semiestruturada e o questionário como técnicas para coleta de dados. A revisão de literatura, por sua vez, concentrou-se em textos relacionados a Música, Educação, Cognição Musical e Medicina.
\end{abstract}

Palavras-chave: Deficiência visual. Performance musical. Musicografia braille. Memória musical.

\section{Introdução}

Neste artigo exponho com brevidade parte de minha pesquisa de Doutorado ${ }^{1}$, defendida no Instituto de Artes da UNESP (São Paulo), em 2019, focalizando as questões que envolvem a performance musical ${ }^{2}$ de pessoas com deficiência visual, como os tipos de deficiência visual (baixa visão e cegueira; deficiência visual congênita e adquirida), musicografia braille, tipos de memória, memória musical e como a memória musical interage no desenvolvimento performático do músico com deficiência visual.

A pesquisa de natureza qualitativa/quantitativa foi embasada nos textos de pesquisadores que atuam com as temáticas relacionadas e pesquisadores de destaque no campo da cognição musical. Ao utilizar a abordagem mista da pesquisa quali/quanti busquei trazer uma maior amplitude investigativa, com uma atuação mais livre, conforme a

\footnotetext{
1 Tese de Doutorado em Música, intitulada A performance musical da pessoa com deficiência visual, defendida em 2019, no Programa de Pós-Graduação em Música do Instituto de Artes da UNESP.

$2 \mathrm{O}$ conceito de performance musical é bastante diversificado, muitas vezes empregado com significado similar aos termos prática musical, execução e interpretação musical. Isso ocorre também em outras línguas, como o inglês e o alemão, nas quais as palavras performance e interpretation (inglês) e vortrag e aufführung (alemão) são utilizadas como termos correlatos. Nesta investigação será adotado o conceito de performance relacionada tanto aos aspectos ligados a interpretação musical quantos aqueles que dizem respeito à prática musical, revelando relações e implicações conceituais existentes no texto musical (LIMA; APRO; CARVALHO, 2006).
} 
necessidade da pesquisa. Neste sentido, Spratt, Walker e Robinson (2004) afirmam que a pesquisa qualitativa/quantitativa busca apreender de forma mais ampla a complexidade da sociedade moderna, amenizando, dessa forma, as deficiências encontradas nas metodologias puramente qualitativas ou quantitativas.

Para tanto, realizei uma série de entrevistas com músicos eruditos e populares com deficiência visual (baixa visão e cegueira). Busquei escolher entrevistados residentes em locais diversos da América Latina e Europa, com diferentes tipos de deficiência visual, a saber: Hermeto Pascoal, com baixa visão; Jorge Gonçalves e Vilson Zattera, com cegueira total; e Marcelo Bratke, que possuía baixa visão até os 44 anos de idade.

Além das entrevistas, elaborei questionários direcionados a alunos de performance musical com deficiência visual, professores de performance musical que atuam ou atuaram com este público e desistentes de cursos de performance musical que apresentam esta deficiência. Podemos afirmar que os questionários são utilizados com frequência no campo da música, como um procedimento altamente indicado para a obtenção de dados relevantes do público consultado. A aplicação dos questionários foi realizada mediante os objetivos da pesquisa, e contou com a participação de 14 Unidades Federativas do país.

Também realizei um levantamento bibliográfico para verificar as pesquisas anteriores que investigaram questões relacionadas com esta temática. Objetivei, com essa pesquisa, investigar os processos educacionais, biológicos e cognitivos presentes na performance dos músicos com deficiência visual, de modo a compreender com maior ênfase, como tais processos se desenvolvem e quais os fatores externos que podem afetá-los.

Realizando uma consulta aos catálogos de teses e dissertações brasileiras, disponibilizados pelos portais da Coordenação de Aperfeiçoamento de Pessoal de Nível Superior (Capes) e da Biblioteca Digital Brasileira de Teses e Dissertações (BDTD), verifiquei que não existia, até o momento, pesquisas referendando os termos performance musical e deficiência visual. Com relação a termos mais abrangentes, como deficiência visual, ensino de música/educação musical e musicografia braille, até o final do ano de 2017, foram publicadas apenas três teses de doutorado (TRINDADE, 2008; BONILHA, 2010; MELO, 2014) e 20 dissertações de mestrado acerca da temática.

Notei ainda que a escassez de materiais científicos produzidos acerca da temática também era algo recorrente em Portugal. Pude comprovar isto na ocasião em que realizei uma comunicação no VII Encontro de Investigação em Música (ENIM), promovido pela Sociedade Portuguesa de Investigação em Música (SPIM), na Universidade do Minho (UMinho), em Braga, Portugal, em novembro de 2017. Na ocasião, pude presenciar duas pesquisadoras portuguesas que estavam desenvolvendo uma pesquisa envolvendo a música e pessoas com deficiência visual, e que tomaram como referencial teórico os materiais 
publicados por pesquisadores brasileiros, como Tudissaki $(2014 ; 2015)$, Bonilha $(2006 ; 2010)$ e Tudissaki e Lima (2012).

Em consulta ao portal dos Repositórios Científicos de Acesso Aberto de Portugal (RCAAP), também não foi encontrada nenhuma pesquisa publicada em Portugal, referendando os termos performance musical e deficiência visual. No que diz respeito aos termos deficiência visual, ensino de música/educação musical e musicografia braille não havia nenhuma tese de doutorado, e apenas três investigações de mestrado (GUERREIRO, 2014; ROCHA, 2016; MAUÁ, 2017).

Com o intuito de ampliar e aprofundar a análise do referencial teórico, entrevistas, questionários aplicados, utilizei a análise de conteúdo, sob a perspectiva adotada por Laurence Bardin (2016) o que me permitiu criar categorias a partir dos discursos relatados e, consequentemente, maior aprofundamento dos temas abordados.

De acordo com Bardin, a análise de conteúdo diz respeito ao conjunto de instrumentos metodológicos cada vez mais sutis e em constante aperfeiçoamento, os quais se aplicam em discursos extremamente diversificados. Ou seja, tudo o que é dito ou escrito pode ser submetido a uma análise de conteúdo. É considerada uma metodologia empírica, dependente do tipo de interpretação que se pretende obter e pode ser definida como um conjunto de técnicas de análise das comunicações que utilizam procedimentos sistemáticos e objetivos de descrição do conteúdo das mensagens, objetivando a inferência de conhecimentos relativos às condições de produção e recepção, recorrendo a indicadores quantitativos ou não (BARDIN, 2016).

Dentre as categorias de análise levantadas a memória musical destacou-se como um dos processos cognitivos imprescindíveis no desenvolvimento performático de músicos com deficiência visual.

Vale destacar que esta pesquisa de Doutorado veio em sequência à pesquisa de Mestrado que realizei no Instituto de Artes da UNESP, no ano de 2014, posteriormente publicada em formato de livro ${ }^{3}$, direcionada a investigar os processos de ensino e aprendizagem destinados à iniciação musical das pessoas com deficiência visual.

\section{A deficiência visual}

Tratando, neste momento, do termo deficiência visual, este é utilizado para uma situação de perda total ou parcial da visão, seja ela congênita ou adquirida ao longo da vida. O nível de acuidade visual pode variar, determinando dois grupos de deficiência visual: 0 grupo das pessoas cegas e o grupo das pessoas com baixa visão (TUDISSAKI, 2015).

\footnotetext{
${ }^{3} \mathrm{O}$ livro apresenta ferramentas pedagógicas para que o educador musical conheça mais sobre a realidade, as necessidades e as adaptações necessárias para as pessoas com deficiência visual, possibilitando experiências musicais significativas em sala de aula (TUDISSAKI, 2015).
} 
No caso da pessoa cega, há perda total ou grande comprometimento na capacidade de enxergar, sendo necessária a utilização do braille para leitura e escrita. Neste sentido, podemos afirmar que os cegos necessitam utilizar os sentidos remanescentes para percepção, análise e compreensão do ambiente, uma vez que não podem contar com a visão.

De modo geral, a cegueira pode ser classificada em: (1) cegueira parcial, na qual os indivíduos só veem vultos, podendo distinguir claro e escuro; (2) próximo da cegueira total, na qual há percepção da luminosidade, sendo capazes de identificar o direcionamento da luz; (3) cegueira total ou amaurose, na qual há perda total da visão (LOPES; SERFATY, 2008).

No caso da baixa visão (também denominada visão subnormal) o indivíduo apresenta comprometimento visual mesmo após tratamento ou correção óptica, como por exemplo, a utilização de óculos ou lentes corretivas, lupas manuais ou eletrônicas, entre outros. A baixa visão pode estar acompanhada de uma alteração no campo visual, como a alteração na visão de cores, na sensibilidade ao contraste ou na adaptação à iluminação (TUDISSAKI, 2015).

Dentre as alterações mais frequentes da baixa visão, destaco:

(1) perda da visão periférica - ocorre, por exemplo, no caso de pessoas acometidas pelo glaucoma e a retinose pigmentária;

(2) perda da visão central - ocorre, por exemplo, no caso de pessoas acometidas pela Degeneração Macular Relacionada à Idade (DMRI) e à doença de Stargardt;

(3) perda Difusa de Campo Visual - ocorre, por exemplo, no caso de pessoas acometidas pela retinopatia diabética;

(4) diminuição global da sensibilidade - ocorre, por exemplo, no caso de pessoas acometidas pela catarata (TUDISSAKI, 2015).

Além das características relacionadas à baixa visão e cegueira, a deficiência visual pode ser congênita ou adquirida, tomando como referência a idade na qual foi adquirida. É válido destacar as semelhanças e diferenças entre os dois tipos de deficiência, já que ambas acarretam características distintas para o processo de desenvolvimento do indivíduo com deficiência visual.

A deficiência visual congênita ocorre quando a criança ainda está no útero materno, na ocasião de seu nascimento ou até os dois anos de idade. Neste caso, a deficiência pode trazer sérias consequências para o desenvolvimento global da criança, especialmente no que diz respeito à construção e formação de conceitos, devido à impossibilidade de acesso às informações do ambiente por meio da visão. Devido a esta deficiência, é imprescindível que a criança interaja e receba estímulos do ambiente em que vive, acessando os sentidos remanescentes, principalmente o tátil cinestésico, o auditivo, o proprioceptivo e o vestibular, logo nos primeiros meses de vida (VIANNA; RODRIGUES, 2008).

No livro publicado em 2015, relatei que entre as causas mais comuns da deficiência visual congênita estão o glaucoma congênito, a retinopatia da prematuridade, a rubéola, a 
catarata congênita, a toxoplasmose congênita, a hipovitaminose $A$, a oncocercose, o sarampo e o tracoma (TUDISSAKI, 2015).

A deficiência visual adquirida ocorre depois do indivíduo ter acesso aos estímulos visuais por algum tempo, ocorrendo, com frequência, na idade adulta. A construção de conceitos e adaptação ao mundo das crianças com este tipo de deficiência visual é facilitada devido à memória visual armazenada e depende do tempo de contato com o mundo que ela teve enquanto enxergava (VIANNA; RODRIGUES, 2008).

As causas mais frequentes para a deficiência visual adquirida são os traumatismos oculares, os ferimentos, o vazamento nos olhos, as perfurações, os processos degenerativos, as alterações secundárias a quadros de hipertensão arterial, o diabetes, as sequelas de infecções oculares, entre outras.

Vale ainda destacar que as dificuldades relacionadas à deficiência visual envolvem não somente o déficit visual propriamente dito, mas também dificuldades de socialização e locomoção, assim como as estereotipias relacionadas à deficiência visual.

\section{Musicografia braille}

A utilização de partituras musicais é algo comum para os músicos, sendo considerada, em muitos casos, como imprescindível para o desenvolvimento musical de um instrumentista ou cantor. Isso ocorre de forma especial quando se trata do estudo voltado à música erudita, quando a leitura e compreensão de partituras musicais é pré-requisito para o ingresso de músicos em orquestras, bandas e outras formações musicais.

No caso das pessoas com baixa visão, estas poderão utilizar partituras ampliadas de acordo com suas necessidades visuais. As pessoas cegas, por sua vez, poderão valer-se da grafia musical em braille, denominada musicografia braille, utilizada para a leitura e escrita de partituras.

A musicografia braille é um sistema de lectoescritura em relevo, criada no século XIX, pelo francês Louis Braille (1809-1852), o mesmo criador do sistema braille. A leitura da musicografia braille funciona de maneira bem semelhante à do braille: são seis pontos em relevo, dispostos em duas colunas verticais e paralelas, compostas de três pontos cada, podendo formar 63 - ou 64 caracteres diferentes, como defendem alguns estudiosos. A pessoa cega utiliza o tato para a leitura dos pontos em relevo, identificando-os código por código.

Este conjunto de seis pontos em relevo é denominado cela braille, enumerados conforme aponta a figura 1: 


\section{(1) (4) \\ (2) (5) \\ (3) (6)}

Figura 1 - Cela braille

(GIL, 2000, p. 43)

O sistema braille é considerado polivalente, pois os mesmos caracteres podem representar letras, símbolos matemáticos, notas musicais etc. E, da mesma forma que na leitura convencional, à tinta, os caracteres em braille são lidos da esquerda para a direita. Entretanto, na musicografia braille ocorre algo diferente da escrita convencional em música, onde a altura das notas varia de acordo posição das notas na pauta e da clave. $\mathrm{Na}$ musicografia braille não há uso de claves e separação entre notas e valores - um único sinal indica o valor da nota e sua respectiva altura (TUDISSAKI, 2015).

Convém mencionar que a musicografia braille passou por uma série de alterações ao longo dos anos, realizadas, inclusive, pelo próprio Louis Braille. Em 2004 o Brasil adotou como referência o Novo Manual Internacional de Musicografia Braille, resultado das pesquisas do Subcomitê sobre musicografia braille da União Mundial de Cegos (UMC).

Apesar de reconhecer a importância da utilização da musicografia braille para músicos cegos, sua utilização não é consenso entre os músicos profissionais, alunos e professores. Prova disto é que pouco mais da metade dos alunos de performance questionados, 65,22\%, utiliza a musicografia em seus estudos performáticos e 100\% dos alunos desistentes nunca utilizou a grafia. Dos professores que responderam ao questionário, $61 \%$ afirmaram utilizar a musicografia braille como ferramenta de estudo para suas aulas de performance, destacandose $o$ fato de que alguns destes professores nem sempre são conhecedores profundos da grafia.

Fica evidente, portanto, a necessidade de que as escolas de música tenham núcleos direcionados à acessibilidade musical destes indivíduos, de modo a auxiliar e facilitar o acesso às partituras em braille para alunos cegos.

Um dos músicos entrevistados em minha pesquisa de doutorado, o pianista português Jorge Gonçalves, cego desde os cinco anos de idade, defende com afinco que o músico cego deve aprender a ler e escrever música assim como qualquer outra pessoa:

Por que é que os cegos têm de arranjar a desculpa que não tem de ler e escrever música? É uma coisa que eu nunca entendi [...]. E a mesma coisa que uma pessoa dizer: 'Ah, eu sei falar, sei ouvir, portanto não preciso escrever as letras!'. Não pode ser assim! E, no estudo da música erudita, isso torna-se ainda mais essencial porque, para mim, é impossível aprender de ouvido porque nós devemos ter muito acesso à articulação, ou seja, à dialética musical do compositor. (GONÇALVES, 2017, apud TUDISSAKI, 2019, p. 191). 
E, apesar de defender a utilização da musicografia braille para o caso dos cegos, Gonçalves não descarta a possibilidade destes tocarem música de ouvido; mas aponta que tocar somente de ouvido pode ser um impeditivo para o caso da pessoa cega querer prosseguir seus estudos e cursar, por exemplo, uma universidade de música.

O entrevistado Vilson Zattera, músico e pesquisador, cego desde os sete anos de idade, também defende a utilização da musicografia braille como fundamental para o músico cego ler, entender e compreender uma partitura musical. De maneira semelhante a Gonçalves, Zattera acredita que compreender a musicografia torna-se primordial para o caso do músico que se dedica à música erudita.

Estes relatos pressupõem a necessidade de o músico cego recorrer à musicografia braille para compreender com maior amplitude a linguagem musical.

A maioria dos professores de performance questionados também acredita que a musicografia pode trazer aos alunos cegos uma maior autonomia, permitindo que eles possam, posteriormente, seguir seus estudos performáticos, visando à profissionalização.

Conforme dito, grande parte dos professores participantes defende a utilização da musicografia braille, apesar de não possuírem conhecimentos aprofundados acerca da grafia. Interessante notar que este fato surge como pouco significativo pelos alunos de performance musical, pois o trabalho de decodificação das partituras em braille deve ser realizado previamente pelo aluno, enquanto nas aulas de performance o professor trabalha as questões técnicas e expressivas das obras.

De maneira diversa aos entrevistados mencionados, o pianista Marcelo Bratke, não utilizava a musicografia braille para conhecer e compreender as obras musicais que executava ao piano. Como nasceu com catarata congênita ${ }^{4}$ e ambliopia ${ }^{5}$, até os 44 anos de idade possuía apenas $7 \%$ de visão no olho esquerdo e $2 \%$ no olho direito. Valendo-se deste resquício de visão e de um ouvido e memória musical absolutamente treinado conseguia tocar concertos bastante longos apenas de memória. Após cirurgia realizada nos Estados Unidos, aos 44 anos de idade, Bratke passou a enxergar $100 \%$ no olho esquerdo e $10 \%$ no direito. Curioso mencionar o fato de que, apesar de enxergar bem com o olho esquerdo, ele afirma ter dificuldades em estudar as partituras musicais da maneira convencional.

\footnotetext{
${ }^{4}$ Catarata - é a opacidade localizada ou generalizada do cristalino e pode ser observada através da pupila, que se torna esbranquiçada. Quando não é congênita, tende a ser progressiva e inicia-se com a diminuição da acuidade visual. Principais sintomas: diminuição da visão, formação de imagens duplas, dificuldades para ver, distinguir cores, para leitura e alteração frequente do grau de óculos (LOPES, SERFATY, 2008, p. 123).

${ }^{5}$ Ambliopia - termo originário do grego, que significa 'visão boba'; também conhecida como 'olho preguiçoso'. É uma disfunção oftálmica caraterizada pela redução ou perda da visão em um dos olhos (unilateral) ou, mais raramente, em ambos (bilateral). Existem diferentes tipos: estrabismo, diferença de erro de refração entre os olhos (alta hipermetropia e astigmatismo), catarata congênita e qualquer outro fator que impeça a formação do foco da imagem na retina. Principais sintomas: visão dupla, embaralhamento visual, embaçamento aos esforços visuais, indivíduos que 'entortam' a cabeça para ver, fecham um olho na claridade e piscam os olhos constantemente (LOPES, SERFATY, 2008, p. 120-121).
} 
Bratke lamenta o fato de não ter aprendido o braille e a musicografia braille, reconhecendo-a como uma ferramenta essencial para o músico cego. Além disso, visualiza a importância de que o professor de música conheça a musicografia braille, de modo a auxiliar o aluno com déficit visual.

Em contrapartida, o entrevistado Favio Shifres, músico e pesquisador argentino no campo da Cognição Musical, não vê a necessidade de que o músico cego conheça a musicografia braille para realizar com excelência uma performance instrumental/vocal. Neste sentido, aponta que os músicos devem conhecer as partituras musicais justamente pelo fato de não terem de memorizar todas as obras a serem executadas; mas que, no caso do músico cego, isso não é possível, pois ele sempre terá de ler a partitura em braille, decodificar e memorizar, para somente depois executar ao instrumento. Além disso, Shifres acredita que a musicografia possa apresentar questões que vão contra a intuição e a linguagem musical, por exemplo, a melodia 'sobe' ou 'desce' - e isso não ocorre na notação em braille. Ou seja, ocorre um esforço cognitivo de alta complexidade para se vincular a notação musical convencional com a musicografia braille, concluindo que "[...] o braille é um código muito fechado, que pode fazer com que muitas pessoas se distanciem [da música] " (SHIFRES, 2016, apud TUDISSAKI, 2019, p. 167, tradução nossa).

Neste sentido, encontramos a opinião de Costa, que acredita não existir sentido na introdução da partitura em braille para a iniciação ao estudo de um instrumento musical:

Não faz sentido algum introduzir a partitura em braille nas aulas de uma criança que
não sabe ainda o código, ou seja, que não está alfabetizada. Dessa forma, ela não
dispõe das ferramentas necessárias para decodificar a partitura [...]. É preciso
harmonizar a premência de se fazer música com a necessidade da partitura. Esta
surgiu para servir àquela. Não se pode perder isso de vista. (COSTA, 2009, p. 53).

Para o músico Hermeto Pascoal, a necessidade do uso de partituras musicais convencionais ou em braille está bastante vinculada à prática de música em conjunto: "Quando é que se precisa ler a partitura? Quando você vai tocar com outras pessoas. Quando você vai tocar sozinho, você não precisa! [...]" (PASCOAL, 2017, apud TUDISSAKI, 2019, p. 167).

Dentre os relatos dos professores, destaca-se um professor de canto, que afirma dispensar o uso da musicografia braille, desenvolvendo um trabalho mais prático e dinâmico em sala de aula. Outro professor menciona não utilizar a musicografia braille em suas aulas de bateria, acreditando que no caso de seu instrumento, a musicografia pode até mesmo atrapalhar o desenvolvimento musical do aluno.

\footnotetext{
${ }^{6}$ Do original em espanhol: "[...] el braille es un código muy cerrado, que puede hacer que mucha gente se distancie" (SHIFRES, 2016, apud TUDISSAKI, 2019, p. 167, tradução nossa).
} 
Um dado interessante coletado a partir dos questionários aplicados aos alunos desistentes de cursos de performance foi que alguns destes afirmaram que gostariam de ter tido a oportunidade de utilizar a musicografia em suas aulas de instrumento/canto. Diante desta constatação reveladora fica a dúvida: será que estes desistentes continuariam seus estudos musicais se tivessem sido estimulados com a utilização da grafia?

Esta e outras indagações surgiram no momento de coleta e análise das entrevistas e questionários, como por exemplo a preocupação de grande parte dos alunos com baixa visão em ter acesso não somente a partituras ampliadas, mas também estudarem a musicografia braille. Estes alunos, tanto os que encontram-se estudando música como os desistentes, alegaram possuir baixa visão relacionada a uma doença degenerativa e, como consequência, estão perdendo a visão dia após dia. Portanto, podemos concluir que estes músicos em formação acreditam que conhecer a musicografia braille poderá auxiliá-los no processo de adaptação de suas necessidades, bem como na transição de 'músico com baixa visão' para 'músico cego'.

Diante dos relatos apresentados, podemos concluir que a utilização (ou não) da musicografia braille dependerá da perspectiva de cada músico. Reconhecemos a importância da musicografia para o estudo performático do instrumento, especialmente no que diz respeito ao estudo das obras eruditas. Entretanto, não descartamos a possibilidade de o músico com deficiência visual tocar de ouvido, especialmente para a execução de música popular.

\section{A memória enquanto processo cognitivo para retenção do conhecimento}

Tendo em vista a importância da memória para os processos cognitivos relacionados à retenção do conhecimento, proponho-me a descrever alguns dos tipos de memória e a que se destinam.

De acordo com os neurocientistas Larry Squire e Eric Kandel (2003), a memória é o processo que permite aos seres humanos se beneficiarem de experiências anteriores para resolver problemas atuais, ou seja, é o processo pelo qual algo aprendido pode se manter ao longo do tempo.

O processo de memorização prevê o envolvimento entre as experiências passadas, de modo a utilizá-las para orientar comportamentos futuros para a autopreservação e proteção do indivíduo. Para o médico e cientista argentino, naturalizado brasileiro, Ivan Izquierdo (2011), memória significa aquisição (aprendizado ou aprendizagem), formação, conservação e evocação de informações. Sob esta perspectiva, o autor defende que o indivíduo somente 'grava' e lembra o que foi aprendido. Podemos, portanto, concluir que o processo de aquisição, armazenamento ou retenção e evocação das informações é imprescindível para o estabelecimento da aprendizagem e da memória. Este processo de armazenamento e 
utilização de informações tende a exigir esforços de áreas múltiplas e diversificadas do cérebro humano.

Os termos atribuídos aos diferentes tipos de memória variam entre os autores; entretanto, é possível notar uma divisão em:

(1) memória de trabalho ou operacional (também chamada de sensorial, icônica ou de curtíssimo prazo);

(2) memória de curto prazo ou recente;

(3) memória de longo prazo ou remota.

Dentre os autores que realizam estudos avançados acerca da memória, destacamos o 'Modelo modal da memória', proposto pelos psicólogos norte-americanos Atkinson e Shiffrin (1968), que dividem a memória em: (1) memória sensorial, (2) memória de curto prazo e (3) memória de longo prazo. A figura 2 aponta as características apresentadas pelo referido modelo:

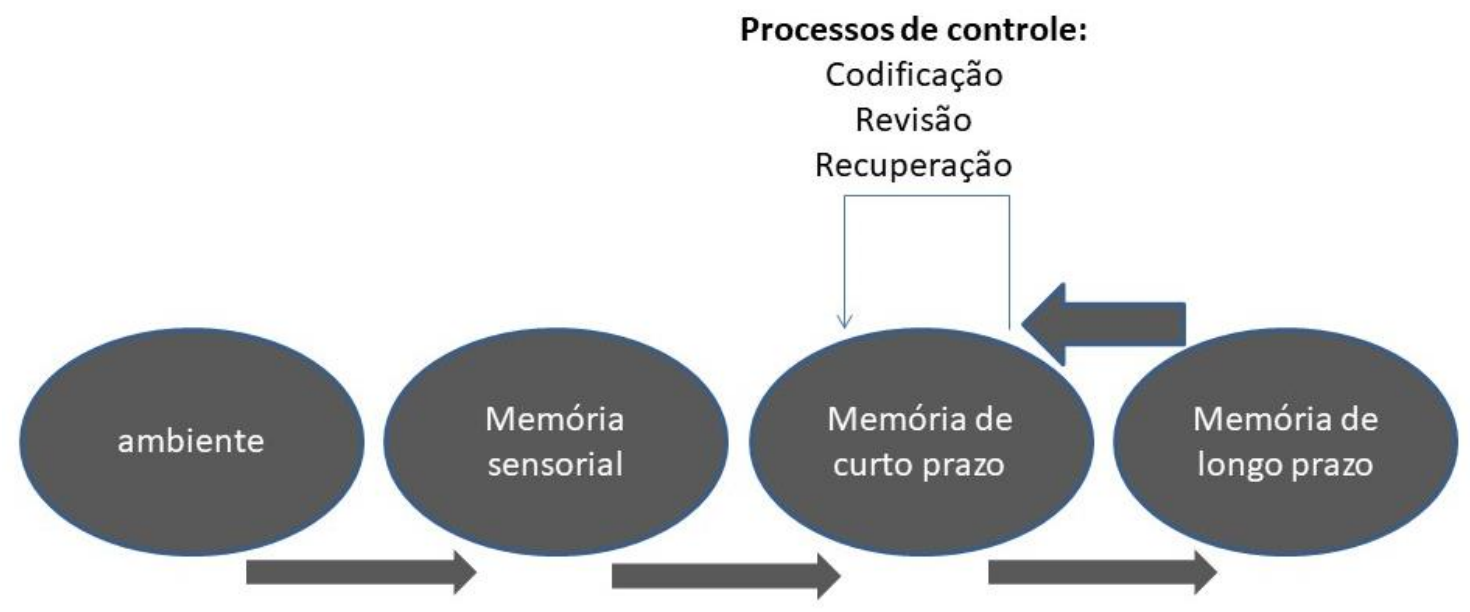

Figura 2 - Memória segundo modelo modal da memória de Atkinson e Shiffrin (ATKINSON; SHIFFRIN, 1968)

Neste modelo, a informação é recebida pelos sentidos responsáveis pelo armazenamento sensorial (odor, paladar, som ou imagem), durando frações de segundos (memória sensorial). Se a informação for necessária ao indivíduo, é selecionada e armazenada na memória de curto prazo, retendo uma quantidade de informação por um tempo curto. Após passar pelo armazenamento de curto prazo, a informação poderá ser esquecida ou passar para o armazenamento de longo prazo, no qual não há limites para armazenamento e pode durar a vida toda. Sob esta perspectiva, o funcionamento da memória está integrado por estruturas interconectadas, responsáveis pela recepção, retenção e recuperação das informações obtidas. 
Neste sentido, podemos inferir que nos processos cognitivos a memória está implícita e permite aos indivíduos interagir com seu meio. Desse modo, está intimamente relacionada à capacidade dos seres humanos registrarem, manterem e evocarem experiências anteriores, bem como ao nível de consciência, atenção e interesse afetivo dos indivíduos.

\section{A memória musical e sua importância para o desenvolvimento performático de músicos com deficiência visual}

No campo da música, a memória engloba aspectos relacionados à percepção sonora e à tomada de consciência ao que foi percebido. Podemos, portanto, relacionar a memória musical aos aspectos emocionais e corporais envolvidos durante a audição e, de modo geral, pode ser considerada parte integrante dos estudos e da profissionalização de um músico, podendo ser até mesmo um pré-requisito em determinadas situações.

Os estudantes, professores e desistentes de cursos de instrumento/canto que participaram dos questionários foram unânimes em apontar a memória musical como um fator essencial para o aprendizado da performance.

O pianista português Jorge Gonçalves, destacou em sua entrevista que existe um mito acerca da memória musical dos cegos, pois é comum acreditar que o cego tem uma memória mais eficiente do que os videntes, observando que nas instituições de ensino de música mais disputadas do mundo o músico performer necessita executar as obras musicais de memória, seja ele cego ou não. Nesse sentido, o performer com deficiência visual é obrigado a desenvolver a sua memória de maneira mais efetiva do que as pessoas que enxergam, mas isso não implica, necessariamente, que a pessoa cega tenha maior capacidade ou uma memória superior simplesmente pelo fato de ser cego.

A musicista e pesquisadora Gisele Marino Costa (2009) compartilha a opinião de Jorge Gonçalves, mencionando o fato de que as pessoas com deficiência visual precisam decorar de maneira imediata endereços ou números de telefone, pois não têm como anotar a informação. Neste sentido, é possível afirmar que a memória apurada é proveniente de um exercício diário, determinado pela necessidade da pessoa com deficiência visual.

O compositor e professor de música Joaquín Zamacois i Soler aponta cinco tipos de memórias musicais: (1) memória reflexiva ou mental - na qual o indivíduo irá arquivar e reter o que pretende memorizar, indispensável para qualquer aprendizado; (2) memória auditiva a qual envolve os sons e ritmos assimilados; (3) memória visual - envolve as imagens retidas pelo músico; (4) memória motora - envolve os movimentos vivenciados e automatizados através da repetição constante; (5) memória afetiva - envolve as sensações projetadas na expressividade do músico (ZAMACOIS, 1973).

A psicóloga e pesquisadora Eliane Leão (2013), por sua vez, acredita que grande parte do conhecimento musical é resultado do desenvolvimento e utilização da memória. Segundo 
a autora, a memória musical depende de outros tipos de memória, a saber: (a) a imagética musical - referente aos aspectos cognitivos da prática musical; (b) memória auditiva operacional ou de curtíssimo prazo - pertinente à memória de trabalho, importante na criação de estruturas e procedimentos composicionais e na execução, percepção e apreciação musical; (c) imagem mental - referente à formação e visualização mental de imagens; (d) a audição mental - o ouvir música com a mente - diferente de se ouvir música produzida por efeito externo; (e) a percepção auditiva - quando processamos a lembrança da altura dos sons para indicar uma melodia ou parte dela; (f) a memória tonal - que veicula estratégias para reconhecimento de tonalidades, ela pode ser considerada um tipo de memória operacional ou de trabalho.

Esta autora defende que os tipos de memórias descritos apresentam como objetivo prover ao performer habilidades tais como antecipações, recuperações e retenções de elementos e estruturas musicais, auxiliando tanto um apreciador leigo em música quanto o performer da mais alta qualidade a práticas musicais de diferentes níveis. Favorece também os grupos de música de conjunto, os regentes e maestros que, utilizando de procedimentos de aprendizagem, chegam a performances musicais apoiadas por subjacentes processos cerebrais de ordem superior (LEÃO, 2013).

$\mathrm{Na}$ entrevista concedida, o músico, professor e pesquisador Vilson Zattera destaca a memória como um recurso essencial para o músico com deficiência visual, especialmente quando se estuda contraponto e harmonia, pois em musicografia braille temos de memorizar o acorde anterior para fazer uma relação com o próximo, e assim por diante.

Conforme dito anteriormente, o pianista Marcelo Bratke nunca utilizou a musicografia braille. Durante a entrevista descreveu que, a fim de desenvolver sua memória musical, costumava utilizar esquemas mentais para decorar as obras musicais que executava:

Quando eu não enxergava bem, eu imaginava a música sem as notas. Imagine você estar ouvindo um rádio num quarto escuro. Aquele som fica na sua memória, aquelas vozes, aquela música. É como uma escultura que começa quando o primeiro som aparece e termina quando o último som desaparece. Esta escultura transforma-se em algo visível dentro do seu cérebro, com alturas, intensidades, cores. Assim é a minha memória musical. Para mim a memória é como uma escultura onde eu pego a primeira forma e vou seguindo na memória, caminhando para a direita. Começa do lado esquerdo e vai para o lado direito e termina no vazio. (BRATKE, 2016; apud TUDISSAKI, 2019, p. 152).

O pianista acrescenta que é a partir destes esquemas que criava era capaz de decorar tudo o que the interessava: "É dentro deste esquema que eu decoro um concerto, que eu decoro o que meu pai falou quando eu tinha doze anos quando nós fomos para a USP, que eu lembro de sonhos que eu tive quando tinha dois anos de idade [...]. É uma memória que eu não sei explicar" (BRATKE, 2016; apud TUDISSAKI, 2019, p. 152). 
Segundo a psicóloga Ana Lúcia Braz (2013), a criação de esquemas pode compor um conjunto organizado de informações acerca de um objeto ou fenômeno. Estes esquemas podem ser designados como representações mentais de um determinado acontecimento, objeto ou processo já consolidado, cujos detalhes poderão ser preenchidos com novas informações.

A memória musical também é parte do discurso dos indivíduos que participaram dos questionários aplicados, especialmente pelos alunos de instrumento/canto. Pelo fato de possuírem a deficiência visual, estes estudantes necessitam realizar a leitura prévia da partitura (ampliada ou em braille), sendo, posteriormente, imprescindível sua memorização, antes mesmo da execução. O músico vidente pode realizar a leitura de uma partitura musical e imediatamente tocá-la em seu instrumento, o que não ocorre com o músico com deficiência visual. Portanto, o desenvolvimento da memória para este instrumentista/cantor é fundamental. Para tanto, grande parte dos alunos questionados destacaram o auxílio do professor de instrumento/canto para a memorização dos trechos musicais, estimulando a percepção auditiva e a memória musical.

Uma questão que merece destaque é a impossibilidade da realização da leitura à primeira vista pelo músico cego. A respeito disso, os músicos e pesquisadores Giesteira, Godall e Zattera afirmam que a utilização da musicografia braille requer ao músico cego muita atenção, memorização, além do tato aguçado:

Uma das desvantagens da musicografia braille é o fato de não poder ler e executar simultaneamente. $\mathrm{O}$ aluno deve memorizar uma passagem musical antes de reproduzi-la, e tal ação exige um grande esforço mental do leitor para que memorize todas as informações em um curto espaço de tempo. ${ }^{7}$ (GIESTEIRA; GODALL; ZATTERA, 2015, p. 141, tradução nossa).

A leitura à primeira vista é bastante solicitada em audições e testes para músicos profissionais, especialmente na área da música erudita. Conforme dito, para o caso de um músico cego esta ação torna-se inviável. Para um músico com baixa visão, se estas partituras não estiverem ampliadas em tamanho e contraste adequado, também encontraremos uma questão problemática para estes indivíduos.

\section{Considerações finais}

A partir das questões apresentadas, a memória musical encontra-se como uma das habilidades essenciais para o músico com deficiência visual, exigindo estudo e dedicação, da mesma forma que as demais habilidades musicais. Justifica-se, portanto, o mito de que as

\footnotetext{
${ }^{7}$ Do original em espanhol: "Uno de los inconvenientes de la escritura musical en Braille, es el hecho de no poder leer y ejecutar simultáneamente. El estudiante tiene que memorizar un pasaje musical antes de reproducirlo, esto requiere del lector un gran esfuerzo mental para memorizar toda la información en un espacio corto de tiempo" (GIESTEIRA; GODALL; ZATTERA, 2015, p. 141, tradução nossa).
} 
pessoas com deficiência visual apresentam maior facilidade de memorização, pelo fato de que, por conta do déficit visual necessitam desenvolver uma memória mais apurada e refinada do que os músicos videntes. Contudo, ao contrário do que se pensa, o músico com deficiência visual não tem uma memória mais apurada do que o músico vidente; ele necessita de constante treino e dedicação, de modo a desenvolver a habilidade da memória e outras habilidades musicais. Neste sentido, conhecer os estudos relacionados à memória pode auxiliar o músico performer a compreender e se reconhecer em tais processos cognitivos.

Além disso, durante a pesquisa realizada, pude inferir que a utilização da musicografia braille para músicos cegos não é consenso. Prova disto é que pouco mais da metade dos alunos de performance questionados, 65,22\%, utiliza a musicografia em seus estudos performáticos e $100 \%$ dos desistentes não a utiliza. Dentre os professores, $61 \%$ afirmaram que seus alunos utilizam a musicografia braille enquanto ferramenta de estudo em suas aulas de performance; ressaltando-se o fato de que a maioria destes profissionais não consiste em profundos conhecedores da grafia. Torna-se evidente, portanto, a necessidade de que as escolas de música possuam núcleos direcionados à acessibilidade musical destes indivíduos, de modo a garantir o acesso às partituras musicais para todos os alunos.

De forma auxiliar, sugiro a utilização de softwares de edição de partituras em braille para o caso de músicos cegos, que podem ser utilizados para o desenvolvimento musical destes, permitindo o acesso às partituras de forma simples e direta. Vale ainda mencionar o fato de que os softwares com maiores recursos apresentam custo elevado, limitando o acesso a grande parte do público interessado.

Apesar disso, a possibilidade de o músico com deficiência visual tocar seu instrumento 'de ouvido' não deve ser descartada. No entanto, o acesso à musicografia braille e às partituras ampliadas pode auxiliar na autonomia do músico cego, fazendo com que este possa ter acesso ao material expresso pelo compositor na partitura. A dificuldade do acesso às partituras em braille também pode ser um fator limitante para que estas pessoas possam se profissionalizar na música, restringindo, por exemplo, seu acesso a uma faculdade de música.

Esperamos que as questões relatadas possam contribuir para que o ensino da performance musical de pessoas com deficiência visual seja investigado por outros pesquisadores e docentes que lidam com esses instrumentistas, não esquecendo que um pesquisador que tenha como meta abordar esta temática deve interagir com outras áreas de conhecimento que the dê suporte; fazendo dessa pesquisa uma investigação de cunho interdisciplinar. Questões biológicas, cognitivas, educacionais, psicológicas e musicais devem ser investigadas contemplando profissionais e pesquisadores de cada uma dessas áreas para que os resultados obtidos possam auxiliar o desenvolvimento musical e performático das pessoas com deficiência visual. 


\section{REFERÊNCIAS}

ATKINSON, R. C.; SHIFFRIN, R. M. Human memory: a proposed system and its control processes. In: SPENCE, K. W.; SPENCE, T. J. (eds.). The psychology of learning and motivation: advances in research and theory. New York: Academic, v. 2, p. 89-195, 1968.

BARDIN, L. Análise de conteúdo (ed. revista e ampliada). Tradução Luís Antero Reto e Augusto Pinheiro. São Paulo: Edições 70, 2016.

BONILHA, F. F. G. Do toque ao som: O ensino da musicografia braille como um caminho para a educação musical inclusiva. 2010. 261 f. Tese (Doutorado em Música) - Instituto de Artes, Universidade Estadual de Campinas, Campinas, 2010.

BONILHA, F. F. G. Leitura musical na ponta dos dedos: caminhos e desafios do ensino de musicografia braille na perspectiva de alunos e professores. 2006. 226 f. Dissertação (Mestrado em Música) - Instituto de Artes, Universidade Estadual de Campinas, Campinas, 2006.

BRAZ, A. L. N. Memória: tipos de atributos. In: LIMA, S. R. A. (Org.). Memória, performance e aprendizado musical: um processo interligado. Jundiaí: Paco, 2013.

COSTA, G. M. Um olhar musical: minhas impressões sobre o ensino de música para deficientes visuais. Belo Horizonte: Ed. do autor, 2009.

GIESTEIRA, A. C.; GODALL, P.; ZATTERA, V. La enseñanza de la musicografía braille: consideraciones sobre la importancia de la escritura musical en braille y la transcripción de materiales didácticos. Revista da ABEM, Londrina, v. 23, n. 34, p. 138-151, jan-jun./2015.

GIL, M. Deficiência visual. Brasília: MEC/Secretaria de Educação à Distância, 2000.

GUERREIRO, R. M. M. O processo ensino-aprendizagem do violino a crianças cegas. 2014. 218 f. Relatório de estágio (Mestrado em Ensino da Música), Instituto Politécnico de Lisboa, Escola Superior de Música de Lisboa, Lisboa, Portugal, 2014.

IZQUIERDO, I. Memória. 2 ed. São Paulo: Artmed, 2011.

LEÃO, E. Aprendizagem e memória: implicações para a educação musical. In: LIMA, S. R. A. (Org.). Memória, performance e aprendizado musical: um processo interligado. Jundiaí: Paco, 2013.

LIMA, S. R. A.; APRO, F.; CARVALHO, M. Performance, prática e interpretação musical: significados e abrangências. In: LIMA, S. R. A. (org.). Performance \& interpretação musical: uma prática interdisciplinar. São Paulo: Musa, 2006.

LOPES, P. C. C.; SERFATY, C. A. Aspectos biológicos da deficiência visual. Rio de Janeiro: UNIRIO, 2008.

MAUÁ, P. E. Ensino de música para cegos sem braile: desafio ou loucura? - a eficácia do ensino de música para adultos com deficiência visual adquirida sem conhecimento de musicografia braile. 2017. 120 f. Dissertação (Mestrado em Comunicação Acessível), Escola Superior de Educação e Ciências Sociais, Instituto Politécnico de Leiria, Leiria, Portugal, 2017.

MELO, M. W. S. Acessibilidade na educação musical para educandos com deficiência visual no contexto da sala de aula. 2014. 236 f. Tese (Doutorado em Educação) - Faculdade de Educação, Universidade Federal da Bahia, Salvador, 2014.

ROCHA, S. S. Estratégias de ensino-aprendizagem da formação musical para alunos cegos e de baixa visão integrados no grupo-turma. 2016. 92 f. Relatório final (Mestrado em Ensino de Música), Instituto Superior de Estudos Interculturais e Transdisciplinares de Viseu, Instituto Piaget, Universidade de Viseu, Viseu, Portugal, 2016.

SPRATT, C.; WALKER, R.; ROBINSON, B. Mixed research methods. Commonwealth of Learning, 2004. Disponível em: http://tutor.nmmu.ac.za/med/Articles/MixedMethods.pdf. Acesso em: 10 out. 2018.

SQUIRE, L.; KANDEL, R. Memória: da mente as moléculas. Porto Alegre: Artmed, 2003. 
TRINDADE, B. G. P. Abordagem musical CLATEC: uma proposta de ensino de música incluindo educandos com deficiência visual. 2008. 402 f. Tese (Doutorado em Educação) - Faculdade de Educação, Universidade Federal da Bahia, Salvador, 2008.

TUDISSAKI, S. E. A performance musical da pessoa com deficiência visual. 2019. Tese (Doutorado em Música) - Instituto de Artes, Universidade Estadual Paulista, São Paulo, 2019.

TUDISSAKI, S. E. Ensino de música para pessoas com deficiência visual. São Paulo: Selo Cultura Acadêmica/Editora Unesp, 2015.

TUDISSAKI, S. E.; LIMA, S. R. A. A Musicografia Braille como recurso pedagógico para a aprendizagem musical de deficientes visuais. In: VIII Encontro Regional Sudeste da Associação Brasileira de Educação Musical, 2012, São Paulo. Anais... São Paulo: Unesp, p. 949-960, 2012.

VIANNA, P. M. M.; RODRIGUES, M. R. C. Psicologia do desenvolvimento e da linguagem do deficiente visual. Rio de Janeiro: UNIRIO, 2008.

ZAMACOIS i SOLER, J. Temas de pedagogía musical. Barcelona: Quiroga, 1973.

\section{A revista ARJ: template para diagramação (título corpo 18 e margens $2,5 \times 2,5 \times 2,5 \times 2,5)$}

\section{Resumo}

Neste artigo discute-se a intertextualidade, objeto teórico, tendo como objeto empírico a relação entre as obras do pintor impressionista Pierre-Auguste Renoir e as de seu filho, o cineasta do realismo poético francês, Jean Renoir. Os dados foram preferencialmente obtidos na exposição Renoir Père et Fils, apresentada no Musée D'Orsay, em 
Paris, de 6 de novembro de 2018 a 27 de janeiro de 2019. Após revisitar a biografia de cada um desses expoentes da arte, foram analisadas brevemente as oito salas da mostra do D'Orsay, destacando as relações entre pai e filho, bem como as extrapolações dessas influências, trazendo outros artistas e escritores cujas obras foram articuladas na obra de Jean Renoir. Por fim, são apresentadas algumas problematizações.

Palavras-chave: Intertextualidade. Pintura. Cinema. Pierre-Auguste Renoir. Jean Renoir. Leitura de Imagens.

Uma flor que no chão cai E retorna à ramada - que nada! Borboleta leve vai...

Arakida Moritake

\section{O fenômeno intertextual}

Analisar e discutir o fenômeno linguístico da intertextualidade traz duas outras questões estéticas e éticas para exame: a originalidade da obra, seja ela literária, visual, musical, cinematográfica, teatral ou outra; e a autoria como propriedade de um criador sobre sua criação. Como se pode perceber, ambas as questões estão interligadas pois, contestada a originalidade por plágio, ou citação, paráfrase, paródia ou outra categoria de intertextualidade em relação a um texto anterior, paralelamente, a autoria está sendo colocada em xeque.

\section{O SUBTÍTULO DENTRO DO SUBTÍTULO}

A arte contemporânea ${ }^{8}$ está entremeada de produções intertextuais, como modo mesmo de questionar a arte, artistas ou trabalhos anteriores a ela. Mas a arte de tempos atrás também se nutriu de narrativas anteriores a ela, pois basta lembrar os casos óbvios das relações entre as produções clássicas gregas e romanas, ao ponto de hoje referenciar-se a uma arte greco-romana; e o caso da retomada de alguns padrões pré-históricos no modernismo, como mostra, entre outros, Ana Claudia de Oliveira, em seu estudo Neolítico: Arte Moderna (1987), título que já antecipa os achados da investigação.

se certas passagens e certos figurinos podem lembrar quadros do meu pai, isto se dá por duas razões: primeiro, porque aquilo se passa em uma época e lugares onde meu pai trabalho muito, na época da sua juventude; depois, é porque sou filho de meu pai e todos são forçosamente influenciado pelos pais.

Se os fenômenos intertextuais em si se dão a partir de um período impreciso, embora ancestral, os estudos sobre as relações entre obras diferentes podem ter como marco fundador dois momentos distintos, o primeiro demarcado pelo linguista russo Mikhail Bakhtin (1895-1975), que data do início do século XX, com a proposição do conceito de dialogia; e o

\footnotetext{
8 Uma nota de rodapé.
} 
outro, postulado pela também linguista, a búlgaro-francesa Julia Kristeva (1941-...), integrante do grupo de intelectuais franceses que se reuniam em torno da revista Tel Quel, ou seja, "tal qual”, expressão que em francês ou português apontam para a intertextualidade. No seio desse grupo, em grande atividade em meados do século XX, Kristeva partiu do conceito bakhtiniano de dialogia e Ihe conferiu características distintas, inaugurando o termo - e o respectivo conceito - de intertextualidade (intertextualité, em francês), delimitando um campo teórico destinado ao estudo de relações entre textos.

\section{A proposta de uma exposição}

Justapor a obra de dois expoentes de duas linguagens diferentes, a pintura e o cinema, foi a proposta do Musée D'Orsay, em Paris, em cartaz de 6 de novembro de 2018 a 27 de janeiro de 2019. Tanto o pintor teve uma produção marcante para a arte do seu tempo, como o cineasta e ator para o seu; ou mesmo, ambos, para a história da arte e para a história do cinema.
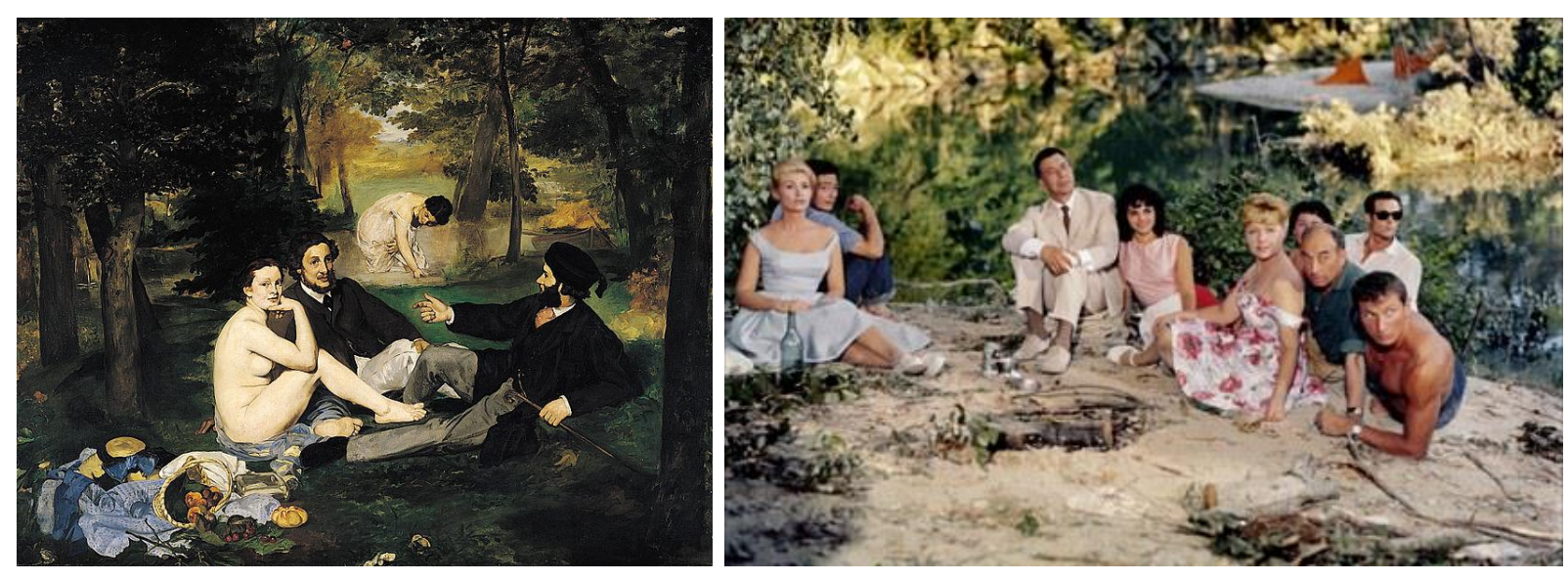

Figura 1 - Le(s) déjeuneur(s) sur l'herbe (1863), tela de Édouard Manet; cena de filme (1959) de Jean Renoir. Fonte: Wikimedia Commons. Disponível em:

https://commons.wikimedia.org/wiki/File:Édouard_Manet_-_Le_Déjeuner_sur_\%27herbe.jpg; The New Yorker. Disponível em: https://www.newyorker.com/culture/richard-brody/watching-sandy-withjean-renoir. Acesso em: fev. 2019.

As inter-relações entre a obra do cineasta Jean Renoir e de seu pai, Pierre-Auguste, merecem análises mais acuradas e com maior aprofundamento. Poderia ser objeto de dissertação ou tese. O que se pretendeu aqui nesta síntese, foi mostrar para um público maior, especialmente para o de língua portuguesa, esse potencial já conhecido, mas sobejamente evidenciado pelo Musée D'Orsay, ou seja, trazer para discussão o pouco que pode ser depreendido de uma visitação a uma exposição de arte, sob a perspectiva dos dois criadores e sob o ponto de vista das relações intertextuais possíveis entre a pintura e o cinema. 


\section{Referências}

BARTHES, Roland. Théorie du texte et intertextuaité. In: RABEAU, Sophie. L'Intertextualité. Paris: Flammarion, 2002.

FEIST, Peter H. Pierre-Auguste Renoir 1841-1919: um sonho de harmonia. São Paulo: Taschen, 1990. 